\title{
Methodologies for modelling energy and amino acid responses in poultry
}

\begin{abstract}
R.M. Gous
Animal and Poultry Science.University of KwaZulu-Natal. South Africa.

ABSTRACT - The objective of this paper is to present some of the issues faced by those whose interest is to predict responses in poultry, concentrating mainly on those related to the prediction of voluntary food intake, as this should be the basis of models designed to optimise both performance and feeding programmes. The value of models designed to predict growth or reproductive performance has been improved inestimably by making food intake an output from, as opposed to an input to, such models. Predicting voluntary food intake requires the potential of the bird to be known, be this the growth of body protein or lipid, the growth of feather protein, or the rate at which yolk and albumen may be deposited daily in the form of an egg, and some of the issues relating to the description of potentials are discussed. This potential defines the nutrients that would be required by the bird on the day, which can be converted to a desired food intake by dividing each requirement by the content of that nutrient in the feed. There will be occasions when the bird will be unable to consume what is required, and predicting the magnitude of these constraints on intake and performance provides the greatest challenge for modellers. This paper concentrates on some issues raised in defining the nutrient requirements of an individual, on constraints such as high temperatures and the social and infectious environment on voluntary food intake, on some recent differences in the response to dietary protein that have been observed between the major broiler strains, and on the methodologies used to deal with populations of birds, and finally with broiler breeder hens, whose food intake is constrained by management, not by the environment. These issues suggest that there are still challenges that lie ahead for those wishing to predict responses to nutrients in poultry. It is imperative, however, that the methods used to measure the numbers that make theories work, and that the theories themselves, are robust and unambiguous such that the resultant models can be used to assist the poultry Industry to become more efficient especially when designing feeds and feeding programmes.
\end{abstract}

\section{Introduction}

Predicting responses of poultry to nutrients has been the goal of nutritionists and modellers for a long time. The controlled feeding model of a growing pig (The Edinburgh Model Pig) was the first serious and successful attempt to integrate information about an animal, its feed and the environment in which it was kept, with a view to simulating its performance (Whittemore, 1976; Whittemore and Fawcett, 1976). This provided the impetus for the development of further models, of modifications to existing models and of research targeted at filling the gaps in our knowledge of critical aspects of the theory incorporated into these models. The most important subsequent contribution to response modelling was the theory proposed by Emmans (1981) (see below) to predict voluntary food intake in poultry and pigs, which raised the value of prediction models inestimably by making food intake an output from, as opposed to an input to, the growth model. Models incorporating this theory are thus more realistic and useful, providing the nutritionist with a tool for making decisions about the most appropriate course of action to take under different circumstances. Advances continue to be made, and it is now possible to optimise the feeds and feeding programmes of broilers and pigs, through the integration of a feed formulation program, a simulation model and an optimisation routine (Gous \& Berhe, 2006). However, because models require a complete statement about each step in the chain of events, some interpolation must of necessity be used where appropriate data are missing (Whittemore, 1981). All models contain some such conjectures, so none can claim to be absolutely accurate. Also, as models become more 
sophisticated, the list of variables that may be predicted increases. Whilst progress in models and modelling has been most impressive, these limitations and opportunities provide modellers with challenges for the future, and some of these are described and discussed here.

Until recently, the mechanistic models developed for pigs and poultry have dealt with the simulation of responses in a single animal or bird. Such responses are usually linear to the point where the genetic potential is reached (Fisher $e t$ al., 1973). Poultry nutritionists are interested in responses to nutrients in economically important outputs such as body weight (or protein) gain, breast meat yield, egg output, food intake and conversion efficiency, numbers of chicks produced per hen, etc. Because such responses are usually measured using groups of birds, they are invariably curvilinear, being the result of integrating the responses of individuals making up that population. Populations of birds therefore cannot have requirements for nutrients: what nutritionists seek are the optimum economic dietary contents of each nutrient, and for this they need to know how populations respond to increasing dietary contents of the essential nutrients. Descriptions of such responses, whilst taking account of marginal costs and revenues, are therefore invaluable in determining how to maximise or minimise the objective function chosen for any given commercial operation. Clearly, being able to predict these nutrient responses may be seen as the foundation of a successful nutritionist.

The objective of this paper is to present some of the issues faced by those whose interest is to predict responses in poultry, concentrating mainly on those related to the prediction of voluntary food intake, as this is the basis of models designed to optimise both performance and feeding programmes.

\section{Predicting voluntary food intake}

To be of any real value, models that attempt to optimise the feeding of broilers and laying hens must be capable of predicting voluntary food intake. Where this variable is an input to the model, as is most often the case, it is naïve to believe that feeding programmes can be successfully optimised, when the composition of the food offered has such important effects on voluntary food intake. Food intake must therefore be an output from a model, and not an input. The theory of food intake and growth proposed by Emmans $(1981,1989)$ was based on the premise that birds attempt to grow at their genetic potential, which would imply that they would attempt to eat as much of a given feed as would be necessary to grow at that rate. Factors that would prevent them from achieving this goal would be the bulkiness of the feed or the inability to lose sufficient heat to the environment in order to enable them to remain in thermal balance. This theory has been shown to predict food intake and hence growth and carcass composition with considerable accuracy (Ferguson \& Gous, 1997, Ferguson et al., 1997). Broilers (Burnham et al., 1992) and laying hens (Gous et al., 1987) have been shown to increase food intake as the limiting nutrient in the feed is reduced, attempting thereby to obtain more of the limiting nutrient, until a dietary concentration is reached where performance is so constrained that food intake falls. The common misconception that birds eat to satisfy their energy requirements is clearly naïve and of no value in predicting voluntary food intake.

In order to predict voluntary food intake it is necessary to describe the genotype, the food being offered, and the environment to which the animal is being subjected. Each of these provides challenges for the modeller, many of which have been described previously (Emmans \& Fisher, 1986). The approach suggested by Emmans (1989) to describe and evaluate broiler genotypes begins with a definition of potential protein growth, and the live weight of the animal is built up from this, using the allometric relationships that exist between protein, water, ash and lipid, i.e. a bottomup approach. He has shown that a few, simple, assumptions can lead to a description of a growing animal that is sufficient for predicting its performance in non-limiting conditions and for calculating what these conditions are. It seems sensible to be able to predict performance in nonlimiting conditions before the more difficult question is tackled, namely, that of defining growth in limiting conditions. Values for the genetic parameters that define a growing animal can be measured by rearing animals in environmental conditions that are as near to ideal as possible. Under these conditions, growth curves are

๑ 2007 Sociedade Brasileira de Zootecnia 
obtained that represent the genetic potential for a particular genotype. The growth curves obtained in this way allow comparisons to be made between breeds and strains. Examples of such investigations are in Hancock et al. (1995), and Gous et al. (1999).

\section{Describing the potential rate of lay}

Describing the potential rate of lay of a laying hen is complex as this differs between individuals and over time within individuals. The mathematical model of Etches and Schoch (1984) demonstrated that two functions, representing two independent but interacting systems of the hen's asynchronous ovulatory cycle, were able to predict realistic ovulation times and intra-sequence ovulation intervals. However, a major disadvantage of their model is that predictions are restricted to sequences of between 2 and 9 ovulations only. For each ovulation sequence, a different set of discrete values for the parameters is required, these values apparently having been somewhat arbitrarily chosen by the authors. Of greater value for modeling purposes is a set of continuous functions, representing the changes required to the values of the different parameters, such that the prediction of any sequence length is possible: in the present paper, such functions are described. This approach (Johnston \& Gous, 2003) has considerably enhanced the value of the model described originally by Etches and Schoch (1984). Mean rate of lay in a flock of hens at a particular age is determined by the individual patterns of sequential laying at that time. The slope of the initial rise in flock egg production to peak rate of lay is influenced by the distribution of ages at sexual maturity and by the lengths of the individual prime sequences. The incidence of internal laying at onset of maturity plays a role in modifying rate of lay but not ovulation rate. The persistency of lay after peak will be determined by the rate at which sequence lengths of individual hens shorten over time, as well as by the number of pause days. Hence the prediction of sequence length is a logical step in predicting the performance of a flock of laying hens over an entire laying cycle.

One of the advantages of the method used by Johnston \& Gous (2003) to model egg production is that it lends itself to stochasticity. Within a population of birds, individuals of the same age show considerable variation about a mean sequence length, which may be due to variation in the length of the open period for LH release, or variation in follicular dynamics. This variance may be accounted for by using mean values and standard errors for each of the parameters in the model. Such a population of birds would generate a range of ovulation times, the distribution of which would be unimodal and positively skew in young hens, becoming bimodal with age. Reproductive senescence in hens manifests as an increase in the intra-sequence ovulation and oviposition intervals with time, as well as an increase in the number of pause days. With this information it is possible to determine the nutrients required daily by laying hens for reproductive purposes.

A growing or reproducing animal needs to be supplied with nutrients in order to meet the requirements for maintenance of the body, for the growth of all other components of the body, including feathers, and for reproduction. The resources needed to meet these requirements can be determined from knowledge of the growth rate and composition of the various components of the body and eggs being produced. The resources available for supplying these requirements, which are present in various feedstuffs, need to be described in the same terms as are used to describe the nutrient requirements.

The requirement for protein depends on the amino acid composition of that protein and the rate at which it is being produced. The sum of each amino acid required for the maintenance and the growth of feather and of body and egg protein constitutes the daily requirement for each of the amino acids. The retention of lipid, water and ash has no protein requirement. The scale on which the amino acids required by the animal are measured, and on which the amino acids in the feed are described must be the same. The conventional wisdom is to express this in terms of digestibility. The marginal efficiency with which the first limiting amino acid is used for protein retention above maintenance is not necessarily constant, but can be modified by the supply of other amino acids and by the supply of energy. Values for these marginal efficiencies need to be measured using response experiments, but the methodologies used for measuring and interpreting

๑ 2007 Sociedade Brasileira de Zootecnia 
such responses have not been resolved, as discussed below.

\section{Measuring and interpreting amino acid responses}

Before nutrient responses can be predicted it is necessary to have some measurements on which theories may be based. Indeed, one of the most important reasons for conducting experiments, apart from testing a theory or comparing two theories, is to determine the numbers that will make a theory work, such as measuring the efficiency of utilisation of the limiting amino acid for protein growth. In this section the measurement and interpretation of amino acid responses will be used as an example of the controversy that still exists in the methodologies used to measure and interpret nutrient responses. For example, the two general methods used to measure responses to individual amino acids are the graded supplementation technique (D'Mello, 1982), where a basal diet deficient in the test amino acid is progressively supplemented with increasing doses of the synthetic form of the test amino acid, and the summit dilution technique (Fisher \& Morris, 1970), in which a summit feed with excessive amounts of all amino acids but with the test amino acid first-limiting is progressively diluted with either a non-protein diluent or a dilution feed with the balance of amino acids reflecting those in the summit feed. Issues have been, and are still being raised regarding these techniques, the most recent review being by D'Mello (2003). His arguments are biased in favour of the graded supplementation technique, arguing that this has been, and remains, the method most often used by nutritionists, and that the summit dilution technique relies on the deliberate imposition of an amino acid imbalance in the summit diet...(this being)...the precise method for the precipitation of deleterious effects in amino acid imbalance (Harper, 1964; D’Mello \& Lewis, 1971, D’Mello, 1990). He fails to mention that the graded supplementation technique also imposes an imbalance with the same potential effects, that this imbalance is considerably greater on the most limiting feed than in the feeds in a dilution series, and that this (im)balance differs in each of the feeding treatments used with that technique. Rogers (1976) makes the point that ...if almost any series of multifactorial experiments is ๑ 2007 Sociedade Brasileira de Zootecnia examined in which a given protein is being supplemented with various amino acids to improve the quality of the protein, amino acid imbalances often become apparent. It has been argued (Fisher \& Morris, 1970; Gous \& Morris, 1985) that the response may well be influenced by this change in amino acid balance.

It is salutary to note that a broiler growth model (EFG Software, 2006), based on the theory of food intake and growth proposed by Emmans (1981), accurately predicts responses in food intake, live weight, protein and lipid gain obtained with the summit dilution technique, but seldom does so when the graded supplementation technique has been used. Because this model takes no account of amino acid imbalances, the responses being directly related to the content of the first-limiting amino acid in the feed, the lack of agreement between observed and predicted responses when using the latter technique provides circumstantial evidence that imbalances are indeed confounding the responses to some amino acids when this technique is used. If the response to nutrients is influenced differentially by the changing amino acid balance in the test feeds, when using the graded supplementation technique, the coefficients of response will be lower than they should be, resulting in an overestimate of the efficiency of utilisation of the limiting nutrient. A comprehensive survey of response trials conducted using both techniques is currently underway at the University of KwaZulu-Natal with a view to identifying the characteristics of the feeds used which result in such unpredictable responses. If responses are influenced by both the level of limiting amino acid in the feed and changes in amino acid balance, then models of food intake must be modified to take account of this confounding. The extent to which imbalances are created differs with the limiting amino acid (Rogers, 1976), so it may be necessary to model this characteristic of feed at the biochemical rather than the whole animal level.

These methodological issues would be resolved by measuring instead the response to balanced protein, thereby eliminating issues of unbalanced or imbalanced amino acid mixtures. This is the approach used by Clark et al. (1982), who used a summit dilution technique and a wellbalanced protein mixture to measure the response 
of broilers to protein, and by Corzo et al. (2004)

\& Lemme et al. (2006). Kemp et al. (2005) and Berhe \& Gous (2005) measured the responses of two strains of broiler to balanced protein and discovered that the strains responded quite differently to these feeds. These differences are discussed in more detail below. Unfortunately, efficiencies of utilisation of individual amino acids cannot be measured unless they are limiting in a feed, but for most other purposes it would seem prudent to measure responses to balanced, rather than unbalanced, protein mixtures.

The reasons for measuring responses are varied and include, among others, the need to determine the efficiency of utilisation of an amino acid, to define the optimum intake of an amino acid for a population and to compare responses between strains or sexes. The method of interpreting these responses would depend on the reason for their measurement, but where the objective is to define the optimum intake of a nutrient, various methods of interpretation of such responses are still used in the literature in spite of the compelling review by Morris (1989) that concludes by pointing out the value of including marginal costs and revenues in such calculations. An integration of the responses of individuals making up a population results in a curved response, the so-called Reading Model of Fisher et al. (1973), making it impossible to define a population requirement for each nutrient no matter what form of equation is used to fit a curve to the data. It is always wrong to fit a broken stick model to a population response, as such a response applies only to an individual and not to a population, resulting in an underestimate of the optimum intake of the nutrient when applied to the population response.

The response to the limiting nutrient, or to balanced protein, may be of considerable interest, but not as a means of defining a requirement. Where marginal costs and revenues are included in the calculation, such responses may be used to determine the optimal economic intake of the nutrient by fitting the Reading Model (Fisher et al., 1973, Morris, 1989) to the data, and this may be of some value in laying hens whose requirements are relatively stable for long periods of time. However, in the case of growing birds the optimal economic intake is meaningless, as, although it may apply to the period over which the trial was conducted, the requirements and hence responses of growing birds are changing continually over time. Such responses are therefore useful for testing theories of food intake and growth, but are of little value in defining a feeding programme for broilers.

In many instances the results of experiments have been used to define the requirement for the class of poultry used in the trial. One should bear in mind that the results of any one experiment are rarely sufficiently robust that they can be universally applied in this way: strain, sex, stocking density, environmental conditions, feeding levels and programmes, among others, all interact to define the response measured, and consequently the method of interpretation used to define the requirement, under the sub-set of conditions applied during the experiment, is of relatively minor importance. The value of such response experiments is therefore not that they enable one to define a requirement, but rather that they can be used for more fundamental purposes, such as to measure the efficiency of utilisation of an amino acid. Because the measurement of response is central to its prediction, it is critical that each experiment is designed in such a way that the results can be used unambiguously when being incorporated into a model. Sensitivity analysis assists in identifying those aspects of a model that are particularly important, and the efficiency of utilisation of amino acids is one such aspect that needs to be accurately estimated. Are the efficiencies the same for all amino acids? Do they differ for growth and reproductive processes? Because doubt has been expressed as to the accuracy of efficiencies measured using the graded supplementation technique, resources need to be applied to resolve this important issue.

\section{Measuring maintenance requirements}

A large proportion of the daily requirement for both energy and amino acids of a broiler and a laying hen comprises that for maintenance. A factorial approach has been used to measure the nutrient requirements for maintenance and either egg production or growth from the results of response experiments such as those of Fisher et al. (1973), Clark et al. (1982) and Boorman \& Burgess (1986), but this is unsatisfactory, especially with growing broilers, because of the

๑) 2007 Sociedade Brasileira de Zootecnia 
changes that take place in the bird both in size and composition over the duration of the experiment. Also, because of differences in the lipid composition of birds on such trials, the use of body weight as a predictor of maintenance is inadequate given that body lipid has no maintenance requirement.

An alternative approach for estimating maintenance coefficients is to measure these independently of either growth or egg production (Gous, 1986). This technique was initially used by Leveille \& Fisher (1960) and by Ishibashi (1973), but the technique used was criticized by Burnham \& Gous (1992) for a number of reasons, one of which was that the response curve for isoleucine was curvilinear indicating that some nutrient other than isoleucine was limiting at the higher input levels. Gous, Fisher \& Broadbent (1984) suggested an improved method for determining maintenance requirements, in which the criticisms leveled against the earlier work were eliminated, and this method was used again by Burnham \& Gous (1992). Essentially the method measures the nitrogen balance of adult roosters subjected to a range of intakes of a diet known to be limiting in the test amino acid, with energy and other essential nutrients, such as vitamins and trace minerals, being supplied ad libitum, to ensure that the birds remain in positive energy balance. The results may be adjusted to provide the coefficient for maintenance per $\mathrm{kg}$ body protein by chemically analysing the carcasses of birds used in such trials, thereby overcoming the problem of differences in carcass fatness. Emmans \& Fisher (1986) suggest the unit of maintenance for both energy and protein (amino acids) is based on the mature protein weight of the bird $\left(\mathrm{P}_{\mathrm{m}}\right)$ and its protein content (excluding feathers) $(\mathrm{P})$ at the time, i.e. $\mathrm{P}_{\mathrm{m}}^{-0.27} \cdot \mathrm{P}$ day, and that this unit should be multiplied by 1.63 to determine the requirement for maintenance energy (MJ/unit), and by 0.008 for maintenance protein (kg/unit).

A comparative slaughter technique has been used by Rabello et al. (2006) for measuring the energy required for maintenance at different environmental temperatures, thereby enabling the determination of the energy required for thermogenesis at low temperatures. The accuracy of this technique is limited because the birds sampled for carcass analysis at the start of the trial

๑ 2007 Sociedade Brasileira de Zootecnia are not the same as those measured at the end of the trial resulting in indeterminate error. However, there does not appear to be a more accurate method for measuring this constant. Rate of laying and egg output decreased linearly in broiler breeder hens given a limited amount of feed daily as environmental temperature was reduced below $19^{\circ} \mathrm{C}$ (Nonis \& Gous, unpublished), this being their means of meeting the increasing requirement for thermogenesis when unable to increase food (energy) intake. Rabello et al. (2006) found the increase in maintenance requirement with decreasing temperature to be curvilinear, but it is difficult to see why this should be anything other than linear, as reported by Sakomura (1989, cited in Rabello et al. 2006) and others. For temperatures above about $19^{\circ} \mathrm{C}$ there should be no need for the bird to consume energy for purposes of thermogenesis, thus a broken stick model would appear to be appropriate for modelling the effect of environmental temperature on energy requirement.

\section{The environment as a constraint to achieving the desired feed intake}

High temperatures are the most common reason for birds and animals not achieving their desired feed intake. It has been demonstrated (Ferguson \& Gous, 1997, 2002, Ferguson et al., $2000 \mathrm{a}, \mathrm{b}$ ) that as the protein or amino acid content of a feed is reduced, pigs will increase intake in an attempt to meet their requirements for potential growth, the extent to which they are able to compensate for the deficiency being dependent on the amount of heat the pig can lose to the environment, which in turn is dependent on the environmental temperature. The results of these experiments are all accurately simulated using the pig growth model (EFG Software, 2006) developed using the theory of growth of Emmans (1981, 1987, 1989).

Whereas birds benefit in cold weather from the insulative properties of their feather cover, this thermal barrier constrains the amount of heat that may be lost to the environment in hot weather. As the potential growth rate of broilers is increased by genetic selection, their inability to lose sufficient heat to the environment is becoming a major constraint in commercial broiler operations worldwide. Accounting for all the factors that 
contribute to the environmental heat demand placed on the birds, such as temperature, humidity, wind speed and thermal radiation, and then accounting for the response of the bird to this effective temperature, is a major challenge when modelling the response of broilers to nutrient supply.

In very few models is food intake an output to the model, the majority needing this variable to be input in some way or other. In such cases it is difficult to imagine that the effects of the environment on food intake can be successfully modelled. But even where food intake is an output, such models presently take a relatively naïve approach when describing the environment, usually describing only the environmental temperature and the relative humidity. Yet wind speed and radiation are important elements in determining the environmental heat demand on the animal, as is the fact that birds are capable of differential blood flow redistribution (McArthur, 1981) to the bare appendages of the body (wattles, comb and legs). By managing the vasoconstriction/vasodilation of the arterio-venous shunts of the skin in those anatomical regions, the bird is able to control sensible heat dissipation (Hillman et al., 1982, Hillman \& Scott, 1989, Willmer et al., 2000). Accounting for these additional factors impacting on the response of the bird to its environment implies that a dynamic approach is necessary.

It is still not clear from the literature what the micro-environmental conditions are at which the bird is at least thermoregulatory effort, which would seem to be a prerequisite for predicting the environmental effects on birds when they are not in this state. Many of the experiments involving the effect of thermal stress on birds have been conducted using constant temperatures applied over long periods of time, which implies that the physiological and productive responses of the bird are in a steady-state (such as the model suggested by Mount (1979) for a homoeothermic animal), thus ignoring the important point that the environment has a dynamic, cumulative effect on chickens (Blanco \& Gous, 2006). These authors have argued that responses of chickens to environmental conditions are dynamic, and depend not only on the thermoregulatory abilities of the birds and the conditions of the environmental variables to which they are exposed, but also on the time of exposure to such conditions. Birds varying in body weight will achieve thermal equilibrium with the environment following different lengths of exposure, depending on the environmental conditions as well as on their thermal properties (feather cover, comb and wattle size, acclimatization, etc). Blanco et al. (2004) have modelled these thermal responses, considering the animal characteristics as well as the environmental conditions.

It appears that there is much still to be done in explaining these thermal responses in a dynamic, time-dependent manner before being able to predict voluntary food intake with precision.

\section{Social and infectious environments}

The basis on which the amino acid requirements for growing and reproducing animals should be calculated is to start with the genetic potential of the animals and to determine what the nutrient requirements would be in order for them to achieve this potential. If no environmental factors constrain performance then this is a sensible method of determining requirements, as the potential performance will be achieved and there will be minimal wastage of valuable nutrients. However, if the animals are subjected to stresses, such as high temperatures, high stocking density, disease and low level infection, potential performance will be reduced. The question then arises whether it would be sensible to adjust the nutrient content of the feed supplied to the animals during the time of stress.

There is ample evidence that the potential performance of animals is reduced when under stress. Examples abound of poorer growth rates at high temperatures, at high stocking densities and when the animals are suffering from an infection. However, little evidence exists of how the animals should be fed under such circumstances. The solution to this dilemma may be approached in two ways: the first is that, because the food intake of the animals will be reduced as a result of the stress, the concentration of nutrients in the feed should be kept the same or even increased under such situations. The second theory proposes that because the potential of the animals will be compromised by the stress there is no reason to supply food with the same nutrient content as would be supplied if they were growing at their

๑ 2007 Sociedade Brasileira de Zootecnia 
potential. Stressors such as stocking density and group size do not appear to reduce the efficiency of utilisation of amino acids in pigs (University of KwaZulu-Natal, unpublished) or broilers (Fisher \& Gous, unpublished), but simply reduce feed intake. These effects may therefore be successfully simulated by reducing the rate of maturing parameter (B) in the Gompertz growth equation, which results in the down-regulation of lean tissue growth (Wellock et al., 2006). In a simulation of these effects (Fisher \& Gous, unpublished), the optimum feed composition was shown to be no different for broilers kept at high stocking densities as for those allowed ample space to grow. But where a slower-growing genotype was used, the optimum composition of feeds differed markedly from that for a fast-growing genotype, yet it was no different for the stocking densities used in the simulation. Therefore the optimum nutrient composition in feeds for broilers kept at high stocking densities, or under other conditions of stress that reduce food intake, does not relate to the apparent reduced potential of the bird, as shown by the difference in optimum feed composition when a slow-growing genotype is used; instead, because the efficiency of utilisation of dietary nutrients is not altered, the optimum dietary composition remains the same. However, not all stressors reduce food intake alone: certain diseases, such as those associated with the digestive and absorptive processes, may cause a reduction in utilisation efficiency and this would be worth exploring further.

A novel approach was used by Sandberg et al. (2006) for predicting the effects of sub-clinical pathogen challenges of different doses and virulence on the relative food intake of animals. This more sophisticated approach to the problem of predicting the effects of an infection on performance models the rate of reduction in food intake as a disease challenge progresses through the animal, enabling actual food intake to be predicted from the relative food intake and animal state. The deductive approach used by Sandberg models differences in the degree of infection, the effect of prior exposure to the organism, and the range over which the population becomes infected, thereby producing a more realistic response to an infection than is obtained by simply reducing the rate of maturing parameter. The pattern of relative

${ }^{\circledR} 2007$ Sociedade Brasileira de Zootecnia food intake during the course of an infection would clearly differ also with the type of infection (viral, bacterial, etc.) and with the tissues or organs targeted. There is scope to take this approach further, and Sandberg et al. (2007) have led the way by identifying the key problems that would need to be solved for predicting the performance of animals exposed to pathogens.

\section{Changes in response brought about through genetic selection}

Recently, Kemp et al. (2005) and Berhe \& Gous (2005) have demonstrated that the Ross 308 strain of broiler does not apparently conform to the theory that birds attempt to consume sufficient of a feed to meet their requirement for the first limiting nutrient in the feed. Instead of increasing food intake as dietary protein content is reduced, this strain reduces intake (Figure 1), resulting in a lower growth rate than in the strain (Cobb 500) whose intake conforms to Emmans' theory.


Figure 1 - Response in food intake of two strains of broiler to increasing dietary balanced protein contents. Trial 1 from Kemp et al. (2005); Trial 2 from Berhe \& Gous (2005). Ross 308 represented by dashed line; Cobb 500, solid line. Dietary protein contents relative to the Ross standard feeding levels (Aviagen, 2006).

The Ross 308 strain has been selected for improved growth and feed efficiency using high protein feeds. Such selection results in leaner 
carcasses (Pym \& Solvens, 1979) and perhaps a reduced ability to fatten when faced with feeds marginally deficient in an essential nutrient. If this were the case then such strains would be incapable of increasing food intake on marginally deficient feeds, as a prerequisite for this is to be able to store the excess energy consumed as body lipid unless the environmental temperature were sufficiently low as to allow the birds to lose the excess energy as heat.

Where two strains are generated using the same values for the Gompertz growth parameters but with differing ratios of maximum lipid: protein in the gain, dissimilar rates of food intake may be simulated under marginally deficient conditions (see Figure 2), but it is apparent that this parameter alone is not sufficient to simulate the widely different patterns of food intake observed in the experiments reported above. Other differences between the strains need to be explored to explain this genotype $\mathrm{x}$ nutrition interaction.

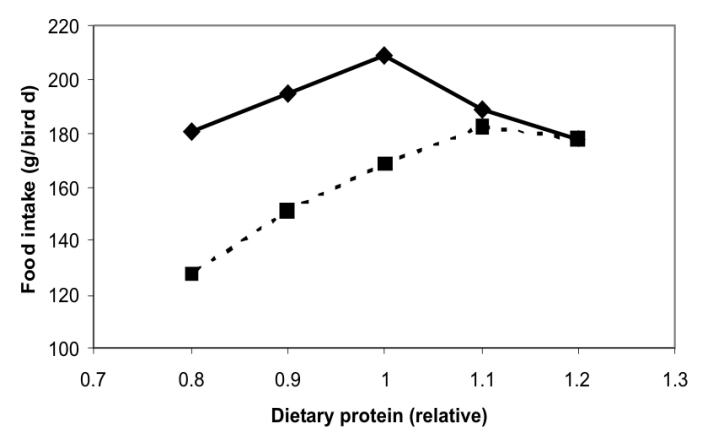

Figure 2 - Simulated food intake by two hypothetical strains of broiler in the period 21 $35 \mathrm{~d}$ of age, offered a range of feeds differing in balanced protein, relative to the Ross standard feeding program (Aviagen, 2006). The strains have the same values for the Gompertz growth parameters, but maximum lipid: protein ratios in the gain are $1.0(\%)$ or $2.0(\%)$.

The decline in food intake with dietary protein content occurs in both simulated strains in Figure 2 , but at different levels of protein feeding. The food intake theory of Emmans (1981, 1987 and 1989) does not preclude a decline in food intake at severely deficient concentrations of the limiting nutrient: it is only on marginally deficient feeds that food intake is predicted to increase. Where the limiting nutrient content is severely deficient, a decline in food intake is expected to occur as a result of the severely constrained growth rates that occur on such feeds, which in turn result in a lower capacity for food intake when measured over a fixed time period. This pattern of food intake, over a range of feeds limiting in an amino acid, is well illustrated in Burnham et al. (1992), being typical of feed intake responses when the summit dilution technique is used to measure such responses, and which are accurately predicted using the theory of food intake of Emmans (1981).

This general response in food intake to decreasing contents of a limiting amino acid, namely, a linear increase followed by a decline in intake, is illustrated in Figure 3. If one assumes that the limiting nutrient content resulting in the lowest food intake on the right of each graph reflects an adequate supply of that nutrient, and that strains may differ in the nutrient content assumed to be adequate, then it is possible to imagine a situation in which the range of nutrient contents chosen in a response trial will result in the food intake increasing and decreasing in the two strains respectively, as illustrated in Figure 3. Whilst this may not be the reason for the difference in their responses in food intake to a limiting nutrient, it does suggest that this may not necessarily be a classical genotype $x$ nutrient interaction. But because of the important implications of these differences when attempting to optimise the feeding of broilers, further investigations of the true cause of these differences are warranted.

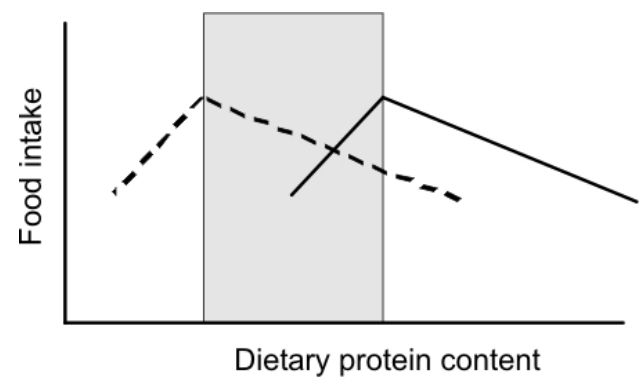

Figure 3 - Simulated responses in food intake to a range of dietary protein contents in two hypothetical broiler strains differing in the dietary protein content required to meet their potential growth. Shaded area reflects a range of dietary protein contents resulting in diametrically opposite food intake patterns in the two strains.

\section{Modelling populations}

Because most nutrition experiments in research and all experiments in commercial poultry production are conducted on groups of birds,

๑) 2007 Sociedade Brasileira de Zootecnia 
models of the response of individuals are not entirely appropriate for application in the poultry industry. For this reason some models have been developed at the level of the group, but a problem with this approach is that the relationships between inputs and outputs for groups are curves, whereas if one assumes that marginal efficiencies for nutrient utilisation are constant, then such relationships are not curves (Emmans \& Fisher, 1986). The Reading Model (Fisher et al., 1973) demonstrated convincingly that the response of an individual (laying hen) differs markedly from that of the population from which the individual is drawn. Whereas the response of each hen to an increasing supply of an amino acid can be assumed to be linear, up to a point where a plateau of output (the genetic potential) is reached, the population response is a continuous, asymptotic curve with no abrupt threshold. This curve results from determining the mean response of a group of individuals at a time. In a population of growing broilers, as with laying hens, there exist differences in the potential output (growth rate) of each animal at a time, but because each bird is growing and food intake is increasing, variation in growth rate is also introduced within each animal over time (Gous \& Morris, 1985), making the need for a population model of broiler growth even more important (or critical) than in the case of laying hens, which are in a relatively steady state. A population model should be built by simulating the responses of many individuals, and not directly as a group, so that the accepted assumptions about marginal efficiencies are not compromised.

But it is not only the variation between individuals in their response to a given feed or environment that controls the variation in the response of a population of birds to a feeding programme in a given environment. Variation also exists in the environmental conditions to which the birds are subjected, as well as the composition of the feed used. Each of these sources of variation need to be addressed when deriving a realistic population response for purposes of optimisation. Details of how each of these sources of variation may be modelled are given in Gous \& Berhe (2006).

Modelling performance in broiler breeder hens

The situation with broiler breeder hens differs from that of broilers and full-fed laying hens in that a daily allowance of feed is allocated to broiler

๑ 2007 Sociedade Brasileira de Zootecnia breeders, this being less than would normally be consumed if the birds were given ad libitum access to feed. Yet the principles applied to voluntary intake prediction, described above, remain: the difference is that the desired food intake of the birds is hardly ever achieved, thus the actual food intake is that constrained by the farm manager. Consequently, egg output will be a function of the amount of limiting nutrient remaining after the maintenance requirement of the hen has been met. It is doubtful that broiler breeders have a requirement for growth, once sexual maturity has been achieved, thus it could be argued that body protein and lipid deposition, or utilisation, leading to a change in body weight, should be regarded as being a consequence of the nutrients consumed and not as an obligatory daily process. This being the case, the balance of ME intake remaining after accounting for maintenance and egg production would be converted into body lipid with varying efficiencies depending on whether the dietary lipid was deposited directly as body lipid or first converted to $\mathrm{CO}_{2}$ and $\mathrm{H}_{2} \mathrm{O}$ (Emmans, 1994). Similarly, any excess protein would be deaminated and converted into body lipid. This is a more sensible approach than assuming that a broiler breeder hen has a need to grow body protein or lipid during the reproductive phase.

All that remains then is to predict potential rate of laying as well as the weights of albumen and yolk that would make up the contents of each egg produced. The methods described by Johnston \& Gous (2006) for this purpose appear to work satisfactorily for broiler breeders (Nonis \& Gous, unpublished) as long as appropriate functions are used to describe the relationships between age and yolk weight, albumen and yolk weight, and shell and egg content weight, which differ between strains. Account can be taken of differences in age at sexual maturity, maximum rates of lay, rates of decay in ovulation rate over time, and the variation that exists between individuals in all these respects. Rules must be applied to account, for example, for minimum egg weights when essential nutrient intake is severely constrained, for the size of amino acid pools for potential albumen formation, and for the rates at which lipid can be either deposited in, or withdrawn from, body reserves as a means of accounting for differences in energy balance. 


\section{Discussion}

It has been 30 years since the Edinburgh Model Pig entered the scientific arena and since then the progress that has been made in predicting performance of broilers and pigs has been enormous. The Edinburgh Broiler Model (Emmans, 1987) was an improvement on the Pig Model, mainly because it predicted voluntary food intake as opposed to using a controlled feeding approach. The theory used to predict food intake (Emmans, 1981) has had major advantages for modellers, as it has been successfully applied in simulating the effect of, among others, changes in dietary amino acid and protein content, environmental temperature, infection and social stress. It has led to food intake being an output from models instead of being an input, which has enabled models to be used to optimise feeds and feeding programmes, a process not possible unless food intake is accurately predicted. It has spawned many useful scientific studies that have corroborated the theory, and it has led to a simplified method of accounting for the heat produced by an animal when consuming a given feed, known as the effective energy system (Emmans, 1994). And because the effective (or net) energy value of a feed is a function of both the feed and the animal being fed, what would be the advantage of describing feeds in these terms if a model were not available to determine the value of this feed to the animal itself? Those early models stimulated useful and purposeful research targeted at filling the gaps in our knowledge of critical aspects of the theory incorporated into these models, this being useful in itself in improving the scientific value of research.

In spite of the progress made in the past decades, there are still challenges that lie ahead for those wishing to predict responses to nutrients in poultry. Many of these have been raised through the development of existing models. For example, the need to understand how to describe the environment and the way it impacts on broiler performance has greater meaning when this information can be linked to a prediction of the constraining effect of high temperatures on voluntary food intake. It has been demonstrated that significant changes have taken place in broiler genotypes over time, and that the genotypes available today differ substantially in their composition and in the way they deal with marginally deficient feeds, yet updating the description of these genotypes would be of little value if this information could not in some way be used to simulate the performance of these birds under varied feeding and environmental conditions, from which optimum feeds and feeding programmes could be predicted. Also, it only really matters whether the efficiency of utilisation of an amino acid by a broiler for growth is 0.75 or 0.80 if this is to be used to predict the requirement by the broiler for that amino acid: this information is of no value if the requirement for the amino acid is being derived purely from the results of a growth trial.

Apart from the problems described above, there are others that still need to be resolved to provide nutritionists with the tools to make informed decisions about poultry feeding. The voluntary food intake of laying hens, for example, has not yet been modelled mechanistically, with nutritionists still relying on empirical equations based on energy requirements such as those of Emmans (1974) as the basis for such prediction. Yet the principles are the same as those for predicting food intake in broilers, the main difference being in the definition of potential performance. But a model has now been developed that adequately describes the ovulatory cycle of a laying hen, from which laying performance and egg composition throughout the laying cycle may be modelled (Johnston \& Gous, 2006). What remains is to model the effect of inadequate nutrient intake on egg production. Similarly, the performance of broiler breeder hens, in response to daily nutrient allocations, needs to be adequately modelled. There remain opportunities for simulation modellers to address these and other challenges in the future.

Sadly, the world does not seem be as enthusiastic about models as are the modellers themselves. This is partially the result of scepticism brought about through bad experiences with (bad) models. Many sets of empirical equations have been termed models, some of which are robust and useful, such as the model to predict age at first egg of laying pullets for any specified pattern of photoperiod used during the rearing period (Lewis et al., 2003), whilst many others are simply equations representing the result of a single

${ }^{\circledR} 2007$ Sociedade Brasileira de Zootecnia 
experiment, with little or no predictive value outside of the experiment itself. It is the latter that have justifiably caused this scepticism. One of the challenges faced by those predicting responses to nutrients is to convince the poultry Industry that good models have the potential to be of immense benefit to nutritionists, geneticists and other decision makers in the Industry. It is imperative that the methods used by scientists to measure the numbers that make theories work are robust and unambiguous such that the resultant models can be used to assist the poultry Industry to become more efficient especially when designing their feeds and feeding programmes.

\section{References}

AVIAGEN. Ross Broiler Management Manual. Aviagen Ltd., Newbridge, UK.2006.

BERHE, E.T.; GOUS, R.M. Effect of dietary protein content on allometric relationships between carcass portions and body protein in Cobb and Ross broilers. 24 $4^{\text {th }}$ Conference of South African Branch of WPSA, Pretoria. 2005.

BLANCO, O.A.; GOUS, R.M.; SAVAGE, M.J. A simulation model for estimating the effect of warm micro-environmental conditions on the heat balance of a broiler. In: Proceedings of the XII World Poultry Congress, Istanbul, Turkey. 2004.

BLANCO, O.A.; GOUS, R.M. Considerations for representing micro-environmental conditions in simulation models for broiler chickens. In Mechanistic Modelling in Pig and Poultry Production (eds RM Gous, TR Morris and C Fisher), pp. 188-208. CABI, Wallingford, UK. 2006.

BOORMAN, K.N.; BURGESS, A.D. Responses to amino acids. In Nutrient Requirements of Poultry and Nutritional Research (eds C Fisher and KN Boorman), pp. 99-123. 1986. Oxford, Butterworths.

BURNHAM, D.; GOUS, R.M. Isoleucine requirements of the chicken. Requirement for maintenance. British Poultry Science, v.33, p.59-69, 1992.

BURNHAM, D.; EMMANS, G.C.; GOUS, R.M. Isoleucine responses in broiler chickens. Interactions with leucine and valine. British Poultry Science, v.33, p71-87, 1992.

CLARK, F.A.; GOUS R.M.; MORRIS T.R. Response of broilers to well balanced protein mixtures. British Poultry Science, v.23, p.433-446, 1982.

CORZO, A.; MCDANIEL, C.D.; KIDD, M.T. et al. Impact of dietary amino acid concentration on growth, carcass yield, and uniformity of broilers. Australian Journal of Agricultural Research, v.55, p.1133-1138, 2004.

D'MELLO, J.P.F. A comparison of two empirical methods of determining amino acid requirements. World's Poultry Science Journal, v.38, p.114-119, 1982.

D’MELLO, J.P.F. Lysine utilisation by broiler chicks. Proceedings of VIII European Poultry Conference, Barcelona, Spain, pp. 302-305, 1990.

D'MELLO, J.P.F. Responses of growing poultry to amino acids. In: Amino Acids in Animal Nutrition (ed JPF D'Mello), Second Edition, pp. 237-263. CABI Publishing, Wallingford, UK. 2003.

D'MELLO, J.P.F.; LEWIS, D. Amino acid interactions in chick nutrition. 4. Growth, food intake and plasma amino acid patterns. British Poultry Science, v.12, p.345-358, 1971.

EFG Software Broiler Growth Model (version 6), Broiler
Nutrition Optimiser (version 1), Pig Growth Model (version 2) and Pig Nutrition Optimiser (version 1). Retrieved January 2007 from www.efgsoftware.net. 2006.

EMMANS, G.C. The effects of temperature on the performance of laying hens. In: Energy Requirements of Poultry (eds TR Morris and BM Freeman), pp. 79-90. British Poultry Science Ltd, Edinburgh. 1974.

EMMANS, G.C. A model of the growth and feed intake of $a d$ libitum fed animals, particularly poultry. In: Computers in Animal Production. pp.103-110. Occasional Publication No. 5. British Society of Animal Production. 1981.

EMMANS, G.C. Growth, body composition and feed intake. World's Poultry Science Journal, v.43, p.208-227, 1987.

EMMANS, G.C. The growth of turkeys. In: Recent Advances in Turkey Science. (eds C Nixey and TC Grey), pp. 135166. Butterworths. 1989.

EMMANS, G.C. Effective energy - a concept of energy utilisation applied across species. British Journal of Nutrition, v.71, p.801-821, 1994.

EMMANS, G.C.; FISHER C. Problems in nutritional theory. In: Nutrient Requirements of Poultry and Nutritional Research. (eds C Fisher and KN Boorman), pp 9-39. (Oxford, Butterworths). 1986.

ETCHES, R.J.; SCHOCH, J.P. A mathematical representation of the ovulatory cycle of the domestic hen. British Poultry Science, v.25, p.65-76, 1984.

FERGUSON, N.S.; ARNOLD, G.A.; LAVERS, G. et al. The response of growing pigs to amino acids as influenced by environmental temperature. 1. Threonine. Animal Science, v.70, p.287-297, 2000a.

FERGUSON, N.; ARNOLD, G.A.; LAVERS, G. et al. The response of growing pigs to amino acids as influenced by environmental temperature. 2. Lysine. Animal Science, v.70, p.299-306, 2000b.

FERGUSON, N.S.; GOUS, R.M. The influence of heat production on voluntary food intake in growing pigs given protein-deficient diets. Animal Science, v.64, p.365-378, 1997.

FERGUSON, N.S.; GOUS, R.M. The response of growing pigs to amino acids as influenced by environmental temperature: tryptophan. Animal Science, v.74, p.103-110, 2002.

FERGUSON, N.S.; GOUS, R.M.; EMMANS, G.C. Predicting the effects of animal variation on growth and food intake in growing pigs using simulation modelling. Animal Science, v.64, p.513-522, 1997.

FISHER, C.; MORRIS, T.R. The determination of the methionine requirement of laying pullets by a diet dilution technique. British Poultry Science, v.11, p.67-82, 1970.

FISHER, C.; MORRIS, T.R.; JENNINGS, R.J. A model for the description and prediction of the response of laying hens to amino acid intake. British Poultry Science, v.14, p.469-484, 1973.

GOUS, R.M. Measurement of response in nutritional experiment. In: Nutrient Requirements of Poultry and Nutritional Research. (eds C Fisher and KN Boorman), pp. 41-57. (Oxford, Butterworths). 1986.

GOUS, R.M.; BERHE, E.T. Modelling populations for purposes of optimisation. In: Mechanistic Modelling in Pig and Poultry Production (eds RM Gous, TR Morris and C Fisher), pp. 76-96. CABI, Wallingford, UK. 2006.

GOUS, R.M.; FISHER, C.; BROADBENT, L.A. Measurement of the amino acid requirement for maintenance of adult cockerels. Proceedings of the XVII World's Poultry Congress, Helsinki, Finland. 1984.

GOUS, R.M.; GRIESSEL, M.; MORRIS, T.R. Effect of dietary energy concentration on the response of laying hens to amino acids. British Poultry Science, v.28, p.427-436, 1987.

GOUS, R.M.; MORRIS, T.R. Evaluation of a diet dilution technique for measuring the response of broiler chickens to increasing concentrations of lysine. British Poultry Science, v.26, p.147-161; 1985.

๑ 2007 Sociedade Brasileira de Zootecnia 
GOUS, R.M.; MORAN, E.T.; STILBORN, H.R. et al. Evaluation of the parameters needed to describe the overall growth, the chemical growth, and the growth of feathers and breast muscles of broilers. Poultry Science, v.78, p.812-821, 1999.

HANCOCK, C.E.; BRADFORD, G.D.; EMMANS, G.C. et al. The evaluation of the growth parameters of six breeds of commercial broiler chickens. British Poultry Science, v.36, p.247-264, 1995.

HARPER, A.E. Amino acid toxicities and imbalances. In: Mammalian Protein Metabolism (eds HN Munro and JB Allison), Vol II, pp. 87-134. Academic Press, New York. 1964.

HILLMAN, P.; SCOTT, N.R. Energy budget of the chicken foot. Journal of Thermal Biology, v.14, p.205-217, 1989.

HILLMAN, P.; SCOTT, N.R.; VAN TIENHOVEN, A. Vasomotion in chicken foot: a dual innervation of arteriovenous anastomoses. American Journal of Physiology, v.242, p.R582-R590; 1982.

ISHIBASHI, I. Amino acid requirements for maintenance of the adult rooster. Japanese Journal of Zootechnical Science, v.44, p.39-49, 1973.

JOHNSTON, S.A.; GOUS, R.M. An improved mathematical model of the ovulatory cycle of the laying hen. British Poultry Science, v.44, p.752- 760, 2003.

JOHNSTON, S.A.; GOUS, R.M. Modelling egg production in laying hens. In: Mechanistic Modelling in Pig and Poultry Production (eds RM Gous, TR Morris and C Fisher), pp. 229- 259. CABI, Wallingford, UK. 2006.

KEMP, C.; FISHER, C.; KENNY, M. Genotype - nutrition interactions in broilers; response to balanced protein in two commercial strains. 15 $^{\text {th }}$ European Symposium on Poultry Nutrition, pp 54-56, Balatonfüred, Hungary. 2005.

LEMME, A.; WIJTTEN. P.J.; WICHEN, J. van et al. Responses of male growing broilers to increasing levels of balanced protein offered as coarse mash or pellets of varying quality. Poultry Science, v.85, p.721-730, 2006.

LEVEILLE, G.A.; FISHER, H. The amino acid requirements of the adult rooster. III. The requirements for leucine, isoleucine, valine and threonine, with reference also to the utilization of the D-isomers of valine, threoning and isoleucine. Journal of Nutrition, v.70, p.135-140; 1960.

LEWIS, P.D.; MORRIS, T.R.; PERRY, G.C. Effect of two opposing changes in photoperiod upon age at first egg in layer-hybrid pullets. Journal of Agricultural Science, Cambridge 140, p.373-379, 2003.

McARTHUR, A.J. Thermal insulation and heat loss from animals. In: Environmental Aspects of Housing for Animal Production (ed JA Clark), pp. 37-60. Butterworths, London. 1981.

MORRIS, T.R. The interpretation of response data from animal feeding trials. In: Recent Developments in Poultry Nutrition (eds DJA Cole and W Haresign), pp.1-11. Butterworths, London. 1989.

MOUNT, L.E. Adaptation to Thermal Environment: Man and his Productive Animals, Edward Arnold, London. 1979.

PYM, R.A.E.; SOLVYNS, A.J. Selection for food conversion in broilers: body composition of birds selected for increased body-weight gain, food consumption and food conversion ratio. British Poultry Science, v.20, p.87-97, 1979.

RABELLO, C.B.V.; SAKOMURA, N.K.; LONGO, F.A. et al. Modelling energy utilisation in broiler breeder hens. British Poultry Science, v.47, p.622-631, 2006.

ROGERS, Q.R. The nutritional and metabolic effects of amino acid imbalances. In: Protein Metabolism and Nutrition (eds DJA Cole DJA, KN Boorman, PJ Buttery, D Lewis, RJ Neale and H Swan), pp 279-301. Butterworths, London. 1976.

SANDBERG, F.; EMMANS, G.C.; KYRIAZAKIS, I. A model for predicting food intake of growing animals during exposure to pathogens. Journal of Animal Science,v.84, p.552-1566, 2006.

SANDBERG, F.; EMMANS, G.C.; KYRIAZAKIS, I. The effects of pathogen challenges on the performance of naïve and immune animals: the problem of prediction. Animal, v.1, n.1, pp.67-86, 2007.

WELLOCK, I.J.; EMMANS, G.C.; KYRIAZAKIS, I. The effects of social stressors on the performance of growing pigs. In: Mechanistic Modelling in Pig and Poultry Production (eds RM Gous, TR Morris and C Fisher), pp. 54-75. CABI, Wallingford, UK. 2006.

WHITTEMORE, C.T. A study of growth responses to nutrient inputs by modelling. Proceedings of the Nutrition Society, v.35, p.383-391, 1976.

WHITTEMORE, C.T.; FAWCET, T.R. Theoretical aspects of a flexible model to simulate protein and lipid growth in pigs. Animal Production, v.22, p.87-96, 1976.

WHITTEMORE, C.T. Animal production response prediction. In: Computers in Animal Production. pp. 47-64. Occasional Publication No. 5. British Society of Animal Production. 1981.

Willmer, P.; Stone, G.; Johnston, L. Environmental Physiology of Animals. Blackwell Science, Oxford. 2000. 